\title{
Gall stones in a Danish population: fertility period, pregnancies, and exogenous female sex hormones
}

\section{T JØRGENSEN}

From the Department of Surgical Gastroenterology D, Herlev Hospital, University of Copenhagen, Copenhagen and The Glostrup Population Studies, Department of Internal Medicine C, Glostrup Hospital, University of Copenhagen, Copenhagen.

SUMMARY From a cross sectional study of gall stone disease ascertained by ultrasonography, the prevalence in relation to age at menarche, use of oral contraceptives, childbirths, breastfeeding, abortions, age at menopause, and menopausal hormone therapy was assessed. The random sample comprised 2301 women of Danish origin aged 30, 40, 50, and 60 years, of whom $1765(77 \%)$ attended the investigation. Gall stone disease was significantly associated with young age at menarche, abortions, and multiple childbirth. Use of oral contraceptives was significantly associated with gall stone disease in univariate analysis, but not in multivariate analysis. Breastfeeding, age at menopause and menopausal hormone therapy were not associated with gall stones. These determining variables seemed sufficient to explain the higher prevalence of gall stone disease in women than in men.

The prevalence of gall stone disease is the same in both sexes until puberty, ${ }^{12}$ but higher in women than in men during the fertility period and after the menopause. ${ }^{34}$ In an attempt to clarify this difference, possible associations between the gall stone disease and fertility period, pregnancies, and exogenous female sex hormones, have previously been evaluated. $\$-20$ Most of these studies comprised clinically diagnosed gall stones only, which implies a risk of diagnostic suspicion bias. ${ }^{2021}$ The few studies, which comprised the overall prevalence of the gall stone disease, were carried out either in a selected group of Italian women, ${ }^{5}$ in a small rural Canadian population, ${ }^{8}$ or among American Indians. ${ }^{1617}$ It was not calculated whether the associations between gall stone disease and the above mentioned variables could explain the sex difference.

In this study, the prevalence of gall stone disease in a random sample of a Danish population was ascertained by ultrasonography. ${ }^{4}$ Estimates were made of possible associations between the gall stones and menarche, menopause, pregnancies, and exogenous

\footnotetext{
Address for correspondence: Torben Jørgensen, The Glostrup Population Studies, Department of Internal Medicine C. KAS Glostrup, DK-2600 Glostrup, Denmark.

Received for publication 16 October 1987.
}

female sex hormones. Additionally it was estimated whether these variables could explain the sex difference observed. ${ }^{4}$

\section{Methods}

SAMPLING AND INVITATION

An age-stratified random sample comprising 2403 women, living in the western part of Copenhagen county, aged $30,40,50$, and 60 years, was drawn on October 151982 from the National Person Register. One hundred and two of foreign extraction were excluded. This reduced the sample to 2301. An equal number of men were invited to the investigation. 4 .

All received a standardised written invitation to a general health examination. Information about the project and a questionnaire, to be completed in advance, was enclosed. Subjects who did not respond were invited again, and those who still did not respond or who refused to participate were contacted by telephone. When they could not be reached by telephone, a new letter was sent asking them to contract us by telephone. The examinations took place between November 1982 and February 1984, at the Glostrup Population Studies. The project was approved by the ethical committee for Copenhagen County. 
Table 1 Prevalence rates $(\%)$ of gall stone disease in women according to age at menarche. $N=$ denominator. Mean: Agestandardised percentages (all Tables)

\begin{tabular}{|c|c|c|c|c|c|c|c|c|c|c|c|c|c|c|}
\hline \multirow[b]{3}{*}{ Age } & \multicolumn{14}{|c|}{ Age at menarche (years) } \\
\hline & \multicolumn{2}{|c|}{$<=11$} & \multicolumn{2}{|l|}{12} & \multicolumn{2}{|l|}{1.3} & \multicolumn{2}{|l|}{14} & \multicolumn{2}{|l|}{15} & \multicolumn{2}{|c|}{$>=16$} & \multirow[b]{2}{*}{$O R$} & \multirow{2}{*}{$\begin{array}{l}\text { Un- } \\
\text { known }\end{array}$} \\
\hline & $\%$ & $N$ & $\%$ & $N$ & $\%$ & $N$ & $\%$ & $N$ & $\%$ & $N$ & $\%$ & $N$ & & \\
\hline 30 & 6.7 & 45 & $4 \cdot 3$ & 70 & 7.9 & 114 & 3.7 & 136 & 1.9 & 53 & 3.8 & 26 & $2 \cdot 08$ & () \\
\hline 40) & $13 \cdot 5$ & 37 & $4 \cdot 1$ & 73 & $7 \cdot 4$ & 95 & 8.7 & 115 & 1.6 & 64 & $4 \cdot 3$ & 47 & 1.29 & 2 \\
\hline 50 & $22 \cdot 2$ & 18 & $12 \cdot 1$ & 33 & $26 \cdot 0$ & 104 & $13 \cdot 2$ & 114 & $12 \cdot 2$ & 82 & $7 \cdot 0$ & 71 & $2 \cdot 30$ & 4 \\
\hline 60 & $45 \cdot 0$ & 20) & $27 \cdot 3$ & 44 & $21 \cdot 7$ & 69 & $17 \cdot 0$ & 112 & $31 \cdot 6$ & 57 & $21 \cdot 4$ & 70 & $1 \cdot 33$ & 6 \\
\hline Mean: & $21 \cdot 9$ & & $12 \cdot()$ & & $15 \cdot 8$ & & $10 \cdot 7$ & & $11 \cdot 8$ & & $9 \cdot 1$ & & & \\
\hline
\end{tabular}

The statistical test and OR compares women younger than 14 years at menarche with women older than 13 years at menarche, being as close as possible to the median value in each age group. Young $><$ old: $\mathrm{M}-\mathrm{H}$ test $=10 \cdot 49, \mathrm{df}=1, \mathrm{p}<0 \cdot 005, \mathrm{OR}=1 \cdot 67(95 \% \operatorname{conf} \mathrm{lim}: 1 \cdot 23-2.28)$.

EXAMINATION AND QUESTIONNAIRE

The upper abdomen was examined by ultrasonography using a Toshiba SAL 20A, real time, linear array scanner with a $2.4 \mathrm{MHz}$ probe. Subjects were classified as having the gall stone disease, when one of the following criteria was fullfilled: (1) Visible gall bladder lumen presenting echoes with an acoustic shadow. The echoes were required to move with gravity, except when obviously impeded by size, a septum, a fold, or wedging into the infundibulum. (2) Non-visualisation of the gall bladder lumen and high density echoes in the gall bladder fossa with acoustic shadow. The echoes were required to have the same relation to the liver when the subject was placed in different positions. (3) No gall bladder lumen in subjects with a history of cholecystectomy and a relevant scar.

Further details about material, non-participants, geographic area, and ultrasonographic criteria and findings have been reported elsewhere. ${ }^{+}$

Subjects with gall stone disease were compared with subjects with a normal gall bladder. History of former and present gall stone disease was recorded. Participants, who had undergone cholecystectomy or had their history of present gall stone disease confirmed ultrasonically, were classified as subjects being aware of their gall stones ("clinical gall stone disease'). Participants, who had no history of gall stones and where they were detected ultrasonically, were classified as subjects being unaware of their gall stones ('non-clinical gall stone disease').

Additional, records were made of age at menarche and menopause, number of childbirths (including stillbirths), length of breastfeeding, number of abortions (spontaneous and induced), use of oral contraceptives (distinguishing between pure progestin and combined progestin/oestrogen preparations), and menopausal hormone therapy.

Women who had undergone hysterectomy before cessation of menstruation were excluded when dealing with age at menopause.

\section{STATISTICAL ANALYSIS}

A Mantel-Haenszel summary $\chi^{2}$ test $(\mathrm{M}-\mathrm{H} \text { test })^{22}$ was used as age was associated with both the outcome variable and the determining variables. ${ }^{23}$ To account for any associations between the independent variables, a multiple logistic regression analysis was done. ${ }^{24}$ Confidence limits were $95 \%$.

\section{Results}

Of 2301 women invited, $1765(77 \%)$ attended the investigation. Among the 536 non-respondents 463 $(86 \%)$ were interviewed by telephone or answered a postal questionnaire. Prevalence of subjects with a history of gall stones was not significantly different among non-respondents as compared with respondents. ${ }^{+}$The overall prevalence rates of gall bladder pathology has been previously reported. Eighty four women had other gall bladder pathology - mainly polyps. ${ }^{4}$ In the analysis below these subjects are omitted.

\section{FERTILITY PERIOD}

Occurrence of gall stone disease increased significantly the younger the age at menarche (Table 1),

Table 2.Prevalence rates (\%) of gall stone disease in women according to age at menopause (young: $<50$ years).

$N=$ denominator

\begin{tabular}{|c|c|c|c|c|c|c|}
\hline \multirow[b]{3}{*}{ Age } & \multicolumn{6}{|c|}{ Age at menopause } \\
\hline & \multicolumn{2}{|l|}{ Old } & \multicolumn{2}{|c|}{ Young } & \multirow[b]{2}{*}{$O R$} & \multirow{2}{*}{$\begin{array}{l}\text { Un- } \\
\text { known }\end{array}$} \\
\hline & $\%$ & $N$ & $\%$ & $N$ & & \\
\hline 50 & $14 \cdot 7$ & 156 & $15 \cdot 2$ & 197 & 0.96 & 0 \\
\hline 60 & $24 \cdot 5$ & 184 & $23 \cdot 0$ & 135 & 1.08 & 0 \\
\hline Mean & 19.6 & & $19 \cdot 1$ & & & \\
\hline
\end{tabular}

Division into young and old was as close as possible to the median value in each age group. Old $><$ young: $\mathrm{M}-\mathrm{H}$ test $=\mathbf{0} \cdot 002, \mathrm{df}=1$, $\mathrm{p}>0.95, \mathrm{OR}=1 \cdot(03,95 \%$ conf lim: $0 \cdot 31-3.43$. 
Table 3 Prevalence rates (\%) of gall stone disease in women according to use of exogene female sex hormones. $N=$ denominator

\begin{tabular}{|c|c|c|c|c|c|c|c|c|c|c|c|}
\hline \multirow[b]{3}{*}{ Type of preparation } & \multirow[b]{3}{*}{ Age } & \multicolumn{10}{|c|}{ Duration of use (years) } \\
\hline & & \multicolumn{2}{|l|}{0} & \multicolumn{2}{|l|}{$1-4$} & \multicolumn{2}{|l|}{$5-8$} & \multicolumn{2}{|l|}{$>=9$} & \multirow[b]{2}{*}{$O R^{*}$} & \multirow{2}{*}{$\begin{array}{l}\text { Un- } \\
\text { known }\end{array}$} \\
\hline & & $\%$ & $N$ & $\%$ & $N$ & $\%$ & $N$ & $\%$ & $N$ & & \\
\hline \multirow[t]{5}{*}{ Oral contraceptives } & 30 & $6 \cdot()$ & 50 & $3 \cdot 8$ & 182 & $6 \cdot 7$ & 105 & $4 \cdot 7$ & 106 & $0 \cdot 80$ & 1 \\
\hline & 40 & 6.4 & 140 & $7 \cdot 1$ & 112 & 5.5 & 73 & 6.5 & 108 & $1 \cdot(01$ & () \\
\hline & 50 & 13.7 & 256 & 17.9 & 67 & $11 \cdot 1$ & 36 & $21 \cdot 5$ & 65 & $1 \cdot 37$ & 2 \\
\hline & 60 & 20.7 & 324 & $4(0 \cdot 9$ & 22 & $25 \cdot()$ & 12 & $47 \cdot 1$ & 17 & $2 \cdot 47$ & 3 \\
\hline & Mean & $11 \cdot 7$ & & $17 \cdot 4$ & & $12 \cdot 1$ & & $20 \cdot 0$ & & & \\
\hline \multirow[t]{3}{*}{ Menopausal hormone therapy } & 50 & 14.9 & 268 & $16 \cdot 5$ & 85 & $18 \cdot 8$ & 48 & $8 \cdot 3$ & 24 & $1 \cdot(08$ & 1 \\
\hline & 60 & 23.6 & 208 & $29 \cdot 7$ & 64 & $22 \cdot 6$ & 31 & $17 \cdot 8$ & 73 & 0.98 & 2 \\
\hline & Mean & $19 \cdot 3$ & & $23 \cdot 1$ & & 20.7 & & $13 \cdot 1$ & & & \\
\hline
\end{tabular}

${ }^{*} \mathrm{OR}$ compares users with non-users in each age-group. Oral contraceptives: Users $><$ non-users: $\mathrm{M}-\mathrm{H}$ test $=4 \cdot 53, \mathrm{df}=1, \mathrm{p}<0 \cdot(\mathbf{0}, \mathrm{OR}=1 \cdot 47$,

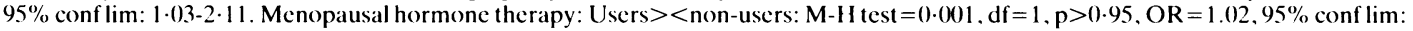
$0 \cdot 25-4 \cdot 26.1-8$ years $><$ more than eight years: $\mathrm{M}-\mathrm{H}$ test $=2 \cdot 74, \mathrm{df}=1, \mathrm{p}>0 .(05, \mathrm{OR}=1 \cdot 86,95 \%$ conf lim: $:(0 \cdot 89-3 \cdot 86$.

Table 4 Prevalence rates (\%) of gall stone disease in women according to use of different types of contraceptive preparations. $N=$ denominator

\begin{tabular}{|c|c|c|c|c|c|c|c|}
\hline \multirow{2}{*}{$\begin{array}{l}\text { Type of } \\
\text { Preparation }\end{array}$} & \multirow[b]{2}{*}{ Age } & \multicolumn{2}{|c|}{ Users } & \multicolumn{2}{|c|}{ Non-users } & \multirow[b]{2}{*}{$O R$} & \multirow{2}{*}{$\begin{array}{l}\text { Un- } \\
\text { known }\end{array}$} \\
\hline & & $\%$ & $N$ & $\%$ & $N$ & & \\
\hline \multicolumn{2}{|c|}{ Oestrogen/progestin 30} & $5 \cdot 0$ & 382 & $4 \cdot 8$ & 62 & $1 \cdot 03$ & () \\
\hline & 40 & $6 \cdot 3$ & 284 & 6.7 & 149 & 0.94 & () \\
\hline & 50 & $18 \cdot 2$ & 165 & $13 \cdot 5$ & 260 & $1 \cdot 43$ & 1 \\
\hline & 60 & $4(1) \cdot 8$ & 49 & $20 \cdot 6$ & 326 & $2 \cdot 67$ & 3 \\
\hline & Mean & $17 \cdot 6$ & & $11 \cdot 4^{*}$ & & & \\
\hline \multirow[t]{5}{*}{ Pure progestin } & 30 & $6 \cdot 9$ & 72 & $4 \cdot 6$ & 371 & $1 \cdot 55$ & 1 \\
\hline & 40 & $10 \cdot 2$ & 49 & $6 \cdot()$ & 384 & $1 \cdot 78$ & 0 \\
\hline & 50 & $23 \cdot 1$ & 13 & $15 \cdot 0$ & 412 & $1 \cdot 69$ & 1 \\
\hline & 60 & $0 \cdot()$ & 2 & $23 \cdot 5$ & 374 & - & 2 \\
\hline & Mean & $10 \cdot 1$ & & \multicolumn{2}{|c|}{$8 \cdot 5+$} & & \\
\hline
\end{tabular}

Users $><$ non-users: ${ }^{*} \mathrm{M}-\mathrm{H}$ test $=5 \cdot 45, \mathrm{df}=1, \mathrm{p}<0 \cdot(05 ; \mathrm{OR}=1 \cdot 53$, $95 \%$ conf lim: $1 \cdot 07-2 \cdot 18 ; \dagger \mathrm{M}-\mathrm{H}$ test $=1 \cdot 66, \mathrm{df}=1, \mathrm{p}>0 \cdot 10$. $\mathrm{OR}=1 \cdot 59.95 \%$ conf lim: $(0 \cdot 79-3 \cdot 19$. whereas no relationship to age at menopause was found (Table 2).

EXOGENOUS FEMALE SEX HORMONES

Significantly higher prevalence of gall stone disease was seen in women who had used oral contraceptives as compared with non-users (Table 3 ). There seemed to be no dose response effect among the users (Table 3 ). Subclassification according to type of contraceptives revealed similar trends, although not statistically significant for pure progestin preparations (Table 4). The overall trend that younger women showed no association between gall stone disease and oral conceptives, whereas older women did (Table 3), was not seen in women using pure progestin preparation (Table 4).

Menopausal hormone therapy showed no substantial relationship to the prevalence of gall stone disease (Table 3). An apparent higher prevalence of

Table 5 Prevalence rates $(\%)$ of gall stone disease in women with $0,1,2,3$, and more than three childbirths, N=denominator

\begin{tabular}{|c|c|c|c|c|c|c|c|c|c|c|c|c|}
\hline \multirow[b]{3}{*}{ Age } & \multicolumn{12}{|c|}{ Childbirths $(n)$} \\
\hline & \multicolumn{2}{|l|}{$\theta$} & \multicolumn{2}{|l|}{$l$} & \multicolumn{2}{|l|}{2} & \multicolumn{2}{|l|}{3} & \multicolumn{2}{|l|}{$>3$} & \multirow[b]{2}{*}{$O R$} & \multirow{2}{*}{$\begin{array}{l}\text { Un- } \\
\text { known }\end{array}$} \\
\hline & $\%$ & $N$ & $\%$ & $N$ & $\%$ & $N$ & $\%$ & $N$ & $\%$ & $N$ & & \\
\hline 30 & $2 \cdot 4$ & 85 & $2 \cdot 1$ & 144 & 5.9 & 170) & 13.8 & 29 & $23 \cdot 1$ & 13 & 3.91 & 3 \\
\hline 40 & $3 \cdot 4$ & 29 & $1 \cdot 2$ & 81 & $7 \cdot 0$ & 227 & 11.4 & 79 & $6 \cdot 3$ & 16 & 4.74 & $i$ \\
\hline 50 & $9 \cdot 1$ & 44 & 15.9 & 69 & $15 \cdot 3$ & 182 & $17 \cdot()$ & 88 & $16 \cdot 3$ & 43 & 1.18 & () \\
\hline 60 & $12 \cdot 5$ & 48 & $16 \cdot 4$ & 73 & $25 \cdot 6$ & 129 & $3(0) 1$ & 73 & 31.4 & 51 & 1.72 & 4 \\
\hline Mean & 6.9 & & 8.9 & & 13.5 & & $18 \cdot 1$ & & $19 \cdot 3$ & & & \\
\hline
\end{tabular}

OR and statistical test compares women having several childbirths ( 30 and 40 years old: $>1$ childbirths, 50 and 60) years old: $>2$ childbirths) with women having few childbirths divided as close as possible to median value in each age group. M-H test $=12 \cdot 55, \mathrm{df}=1, \mathrm{p}<0 \cdot(0005$, $\mathrm{OR}=1 \cdot 84,95 \%$ conf $\lim : 1 \cdot 31-2 \cdot 57$. 
gall stone disease in women using hormones for a shorter period as compared with a longer period, was not significant.

PREGNANCIES AND BREASTFEEDING

Prevalence of gall stone disease increased significantly with number of childbirths (Table 5) and abortions (Table 6). Mean prevalence of gall stone disease among women who breastfed their children was $13.4 \%$ as compared with $9.5 \%$ among parous women who did not (M-H test: $3 \cdot 28, \mathrm{df}=1, \mathrm{p}>0.05$, $\mathrm{OR}=1 \cdot 48(95 \%$ conf lim: 0.97-2.25)).

\section{LOGISTIC REGRESSION ANALYSIS}

The following variables were included in a logistic regression analysis: age at menarche, use of oral contraceptives, childbirths, breastfeeding, abortions, and menopausal hormone therapy.

Table 6 Prevalence rates (\%) of gall stone disease in women with 0,1 and more than 1 abortion. $N=$ denominator

\begin{tabular}{|c|c|c|c|c|c|c|c|c|}
\hline \multirow[b]{3}{*}{ Age } & \multicolumn{8}{|c|}{ Abortions (n) } \\
\hline & \multicolumn{2}{|l|}{0} & \multicolumn{2}{|l|}{1} & \multicolumn{2}{|l|}{$>1$} & \multirow[b]{2}{*}{$O R$} & \multirow{2}{*}{$\begin{array}{l}\text { Un- } \\
\text { known }\end{array}$} \\
\hline & $\%$ & $N$ & $\%$ & $N$ & $\%$ & $N$ & & \\
\hline 30 & $4 \cdot 1$ & 291 & $8 \cdot 5$ & 106 & $2 \cdot 1$ & 47 & 1.63 & 0 \\
\hline 40 & $4 \cdot 2$ & 259 & $10 \cdot 7$ & 112 & $8 \cdot 2$ & 61 & $2 \cdot 46$ & 1 \\
\hline 50 & $11 \cdot 3$ & 240 & $18 \cdot 5$ & 108 & $23 \cdot 4$ & 77 & $2 \cdot 04$ & 1 \\
\hline 60 & $20 \cdot 3$ & 237 & $25 \cdot 0$ & 88 & $36 \cdot 0$ & 50 & $1 \cdot 61$ & 3 \\
\hline Mean & & $10 \cdot 0$ & & $15 \cdot 7$ & & & & \\
\hline
\end{tabular}

OR and statistical test compares women having abortion with women not having abortions. $\mathrm{M}-\mathrm{H}$ test $=15 \cdot 54, \mathrm{df}=1, \mathrm{p}<0.0005$, $\mathrm{OR}=1 \cdot 86,95 \%$ conf lim: $1 \cdot 37-2.53$.

Table 7 Results of the logistic regression analysis in women

\begin{tabular}{|c|c|c|c|c|c|}
\hline Variables & $\begin{array}{l}\text { Log } \\
\text { coeff }\end{array}$ & $S E$ & $O R$ & $p$ value & $\chi^{2 *}$ \\
\hline \multicolumn{6}{|l|}{ Age (yr) } \\
\hline $40 v 30$ & $0 \cdot 1183$ & 0.3043 & $1 \cdot 13$ & $0 \cdot 6974$ & \\
\hline $50 \vee 30$ & $1 \cdot 2957$ & 0.2903 & $3 \cdot 65$ & 0.0000 & $57 \cdot 43$ \\
\hline $60 v 30$ & 1.9461 & 0.3128 & $7 \cdot 00$ & 0.0000 & \\
\hline $\begin{array}{l}\text { Familial occurrence } \\
\quad(\text { yes }><\text { no })\end{array}$ & 0.5210 & 0.1715 & 1.68 & 0.0024 & $9 \cdot 23$ \\
\hline Childbirths & $0 \cdot 2247$ & 0.0678 & $1 \cdot 25$ & 0.0009 & $10 \cdot 98$ \\
\hline Abortions & $0 \cdot 1849$ & 0.0737 & $1 \cdot 20$ & $0 \cdot 0121$ & $6 \cdot 29$ \\
\hline Age at menarche & $-0 \cdot 1180$ & 0.0514 & 0.89 & 0.0216 & $5 \cdot 27$ \\
\hline $\begin{array}{l}\text { Oral contraception } \\
\quad(\text { yes }><\text { no })\end{array}$ & 0.3210 & $0 \cdot 1914$ & $1 \cdot 38$ & 0.0935 & $2 \cdot 81$ \\
\hline Breastfeeding (yes $><$ no) & 0.0049 & $0 \cdot 1889$ & $1 \cdot 00$ & 0.9834 & $0 \cdot 00$ \\
\hline $\begin{array}{l}\text { Menopausal hormone } \\
\text { therapy }(\text { yes }><\text { no })\end{array}$ & -0.0593 & $0 \cdot 1889$ & 0.94 & 0.7534 & $0 \cdot 10$ \\
\hline
\end{tabular}

When oral contraceptives was separated into progestin/oestrogen and pure progestin preparations, neither showed significant association with gall stone disease in the above analysis. Childbirths, abortions, and age at menarche are entered as continuous variables. ${ }^{*}$ Change in $\chi^{2}$ if the variable is removed from the model.
Table 8 Proportion (\%) of women with clinical gall stone disease/total gall stone disease, according to age at menarche (low: $<14$ years), ever used oral contraceptives, childbirths (few: $<2$ for women aged 30 years, $<3$ for women aged 40-60 years) abortions, and ever used menopausal hormone therapy. Divisions in low/high and few/many were as close to the median value as possible. $N=$ denominator

\begin{tabular}{|c|c|c|c|c|c|c|c|}
\hline 30 & 40 & & 50 & & 60 & & \\
\hline$\% \quad N$ & $\%$ & $N$ & $\%$ & $N$ & $\%$ & $N$ & $X^{2}$ and $O R^{*}$ \\
\hline
\end{tabular}

Age at menarche

$\begin{array}{lllllllllll}\text { Young 20.0 } & 15 & 53.3 & 15 & 60.0 & 35 & 44.4 & 36 & 44.4 & 0.01 \dagger & 1.08\end{array}$

$\begin{array}{llrlllllll}\text { Old } & 28.6 & 7 & 30 \cdot 8 & 13 & 46 \cdot 7 & 30 & 55.8 & 52 & 40.5\end{array}$

$\begin{array}{lllll}\text { OR§ } & 0.63 & 2.57 & 1.71 & 0.63\end{array}$

Anticonception (progestin/oestrogen)

Yes $\quad \begin{array}{lllllllllll}26.3 & 19 & 44.4 & 18 & 53.3 & 30 & 42.9 & 21 & 41.7 & 0.04 \dagger & 0.90\end{array}$

$\begin{array}{llllllllll}\text { No } & 0.0 & 3 & 40 \cdot 0 & 10 & 54.3 & 35 & 53.7 & 67 & 37.0\end{array}$

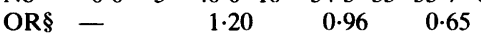

Anticonception (pure progestin)

$\begin{array}{lllrrrrrrrrr}\text { Yes } & 60.0 & 5 & 100.0 & 5 & 100.0 & 3 & 0.0 & 0 & 86.7 & 10.03 \ddagger & 8.61\end{array}$ $\begin{array}{llllllllll}\text { No } & 11.8 & 17 & 30.4 & 23 & 51.6 & 62 & 51.1 & 88 & 36 \cdot 2\end{array}$

OR§ $11 \cdot 30$

Childbirths

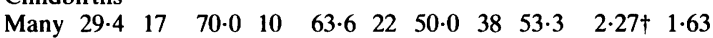

$\begin{array}{lrrrrrrrrr}\text { Few } & 0.0 & 5 & 27.8 & 18 & 48.8 & 43 & 51.0 & 51 & 31.9\end{array}$

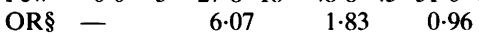

Abortions

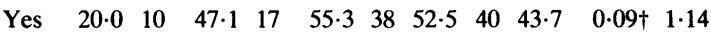

$\begin{array}{llllllllll}\text { No } & 25.0 & 12 & 36.4 & 11 & 51.9 & 27 & 50.0 & 48 & 40 \cdot 8\end{array}$

$\begin{array}{lllll}\text { OR§ } & 0.75 & 1.56 & 1.15 & 1.11\end{array}$

Menopausal hormone therapy

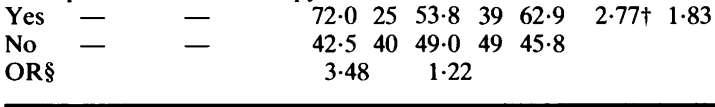

${ }^{*}$ Mantel-Haenszel summary $\chi^{2}$ test, $\mathrm{df}=1 ; \nmid \mathrm{p}>0.05 ; \ddagger \mathrm{p}<0.005 ; \S \mathrm{OR}$ for each age group.

Additionally, age ${ }^{4}$ and familial occurrence of clinically diagnosed gall stones, ${ }^{25}$ previously shown to be associated with the gall stone disease, were included in the analysis. Age, familial occurrence, age at menarche, number of childbirths, and abortions, remained significantly associated with the gall stone disease, whereas intake of oral contraceptives did not. Breastfeeding and menopausal hormone therapy remained unrelated to the gall stone disease (Table 7).

SEX DIFFERENCE

To evaluate whether these determining variables could explain the observed sex difference in gall stone prevalence ${ }^{4}$ a logistic regréssion analysis was carried out including both sexes. Among men, use of exogenous female sex hormones, childbirths, breastfeeding, and abortions were zero, whereas age at menarche was made 14 years, being the median value in women. The analysis revealed that the initial 
significant sex difference in prevalence of gall stone disease (women $><$ men: $\log \operatorname{coeff}=0.8659, \mathrm{SE}=$ $0 \cdot 1290, \mathrm{OR}=2 \cdot 38, \mathrm{p}$ value $=0 \cdot 0000)$ disappeared (women $><$ men: $\log \operatorname{coeff}=0 \cdot 1038, \mathrm{SE}=0.2487$, $\mathrm{OR}=1 \cdot 11, \mathrm{p}=0 \cdot 6763)$.

\section{CLINICAL VERSUS NON-CLINICAL GALL STONE} DISEASE

The overall trend showed that more cases of gall stone disease were diagnosed than not when women had more childbirths and abortions, had used exogenous female sex hormones, and were young at the menarche (Table 8). As regards contraceptives and childbirths the trend was only seen in younger age groups. The trend was only statistically significant as regards pure progestine contraceptives.

\section{Discussion}

\section{FERTILITY PERIOD}

The lack of discernible association between age at menopause and gall stone disease, is in accordance with other findings. ${ }^{57}$ The exact age at menopause can often be difficult to establish because of hormone substitution therapy or hysterectomy before cessation of menstruation. The value of this variable is, therefore, doubtful. Age at menarche does not pose such difficulties. The present finding of increasing prevalence of gall stones with younger age at menarche suggests that gall stone disease is associated with the length of fertility period per se. Findings of increased lithogenic index in bile during the fertility period ${ }^{2627}$ support this assumption, but a previously shown association between obesity and early menarche ${ }^{28}$ could be a confounding factor. No relationship between length of 'the period of natural ovarian activity' and the gall stone disease was observed in one study. ${ }^{\circ}$ To obtain this period, the authors, among other factors, subtracted periods of pregnancies. As more pregnancies imply a shorter period of natural ovarian activity and at the same time a greater risk of gall stones, however, such calculations are of doubtful value.

\section{EXOGENOUS FEMALE SEX HORMONES}

In this study, the use of oral contraceptives and gall stones showed a significant positive association, which proved to be insignificant in the multivariate analysis. A similar non-significant relation was found in a study of the overall prevalence of gall stones in a selected group of Italian women, ${ }^{5}$ whereas no relationship could be shown in a small rural caucasian population. ${ }^{*}$ Studies, comprising of clinically diagnosed gall stones, have shown a positive association between oral contraceptives and gall stone disease; ${ }^{911}$ some have shown possible relationship,${ }^{611}$ whereas others found no association. ${ }^{12-14}$ Results from cohort studies of clinically diagnosed gall stones may very well be inaccurate, as more than half of all subjects with the gall stones are unaware of it ${ }^{+}$and thus classified as not having the disease. In the same studies, there is a risk of diagnostic suspicion bias if the presence of a clinical condition alters the choice of diagnostic procedure in subjects with abdominal complaints. ${ }^{40}$ The present finding that use of oral contraceptives was positively associated with awareness of the disease in younger women (Table 8), may be explained by the above bias. Had the present study aimed at clinically diagnosed gall stones only, it could have left the impression that gall stone disease was associated with intake of oral contraceptives in younger women only, as postulated in a case control study. ${ }^{\circ}$ The observed trend in the present study that younger women showed no association between gall stone disease and oral contraceptives whereas older women did, could be explained in different ways: (1) A chance phenomenon. (2) Slow growth rate of gall stones before reaching detectability. (3) Changes in dose and type of oestrogen and progestin in oral contraceptives during the past years. (4) No causal relationship exists between oral contraceptives and formation of gall stones, but women using oral contraceptives in former periods were - in different aspects - not comparable with the women using oral contraceptives today. This view of no causal relationship is supported by the fact that no dose response effect was observed among users. Studies of the overall incidence of gall stone disease are needed to solve this problem.

Lithogenic index of the bile is increased during intake of oral contraceptives. ${ }^{24-33}$ One study ${ }^{31}$ showed delayed emptying of the gall bladder in users compared with non-users of oral contraceptives, whereas three others did not. ${ }^{3+36}$

If a causal relationship between oral contraceptives and gall stone disease does exist, is it oestrogen, progestin, or both being responsible? No cohort or case control studies have so far dealt with this problem. Oestrogen in doses normally used in oral contraceptives, increased the lithogenic index of bile in men, ${ }^{37}$ but not in women, ${ }^{38}$ in whom larger doses of oestrogen were needed. ${ }^{34}$ Progestin in doses normally used in oral contraceptives increased the lithogenic index of bile ${ }^{3 x}$ in women, and reduced contractability of the human gall bladder wall in vitro." These studies suggest that progestin, and not oestrogen, might be responsible for a possible association between the gall stones and use of oral contraceptives. The present findings are in support of this view, because gall stone disease tended to be positively associated with the use of both combined oestrogen/ progestin and progestin preparations, but not with 
menopausal hormone therapy, which mainly was pure oestrogen preparations. Combined oestrogen/ progestin preparations for menopausal therapy have been prescribed in Denmark only since 1976 and were still not dominant during the study period.

The lack of association between the gall stone disease and menopausal hormone therapy in the present study, is in accordance with other findings, ${ }^{6}{ }^{12}$ whereas one study ${ }^{15}$ has shown a relationship between oestrogen therapy within the last three months before discharge from a hospital with a gall stone diagnosis. In men treated with oestrogen ${ }^{11}+2$ an association with clinically diagnosed gall stones has been found, but the relationship disappeared when the total gall stone prevalence, as found by autopsy, was used for calculations. ${ }^{+2}$ This is in accordance with the trend of the present findings, where menopausal hormone therapy was more frequent in women, who had their gall stones diagnosed, than women who had not. This might be explained by diagnostic suspicion bias or by oestrogen inducing abdominal symptoms either generally or in subjects already having gall stones.

CHILDBIRTH AND ABORTION

The present study showed an increasing prevalence of gall stone disease with numbers of childbirths and abortions. This gains support from a study of the overall prevalence of gall stones in a selected group of Italian women, ${ }^{5}$ whereas findings in American Indians have been inconsistent. ${ }^{16} 17$ Most cohort studies of clinically diagnosed gall stones and case control studies, showed an association between gall stones and number of pregnancies, ${ }^{6718-20}$ whereas two did not. ${ }^{12}{ }^{13}$ Lithogenic index of the bile was higher, ${ }^{43}$ gall bladder volume was larger, and emptying of the gall bladder was more frequently impaired ${ }^{3+35+4 t 6}$ in pregnant women as compared with non-pregnant women. The impaired gall bladder function was seen already within the first few weeks of pregnancy, ${ }^{34}, 35$ which supports the present findings of a relationship between abortions and gall stone disease.

That the sex difference in prevalence could be explained by the above discussed variables, support the observations of equal prevalence of gall stone disease in the two sexes before puberty ${ }^{12}$ and an apparent equal incidence after the menopause.

It can be concluded that number of pregnancies and length of fertility period are associated with gall stone disease. Use of oral contraceptives may be associated with gall stones although the relationship is not substantial. If there is an association, progestin, and not oestrogen may be responsible. Gall stone disease was not associated with breastfeeding, age at menopause, or menopausal hormone therapy. The determining variables seem sufficient to explain the higher prevalence of gall stone disease in women as compared with men.

This survey was supported by grants from Danish Medical Research Council (12-7173, 12-5786); the Danish Hospital Foundation for Medical Research: Region of Copenhagen, the Faroe Islands and Greenland (23/81. 37/83, 45/84); the Danish Health Insurance Foundation (H 11/12-82, H 11/37-83, H 11/38-83; Leo Pharmaceutical Products (1982), and the Foundation of 1870 (AG 120/81). The author thanks Drs Thorkild IA Sørensen and Per Thorvaldsen for helpful comments on the manuscript.

\section{References}

1 Nilsson S. Gallbladder disease and sex hormons. Acta Chir Scand 1966; 132: 275-9.

2 Giunchi G. Findings on gallstone disease in the ISTAT investigation. In: Capocaccia L, Ricci G, Angelico F, Angelico M, Attili AF, eds. Epidemiology and prevention of gallstone disease. Lancaster: MTP Press Limited, 1984.

3 Barbara L. Epidemiology of gallstone disease: The 'Sirmione study'. In: Capocaccia L, Ricci G, Angelico F, Angelico M, Attili AF, eds. Epidemiology and prevention of gallstone disease. Lancaster: MTP Press Limited, 1984.

4 Jørgensen T. Prevalence of gallstones in a Danish population. Am J Epidemiol. 1987: 126: 912-21.

5 GREPCO. Prevalence of gallstone disease in an Italian adult female population. Am J Epidemiol 1984; 119: $796-805$

6 Scragg RKR, McMichael AJ, Seamark RF. Oral contraceptives, pregnancy, and endogenous oestrogen in gall stone disease - a case-control study. $\mathrm{Br}$ Med J 1984; 288: 1795-9.

7 Friedman GD, Kannel WB, Dawber TR. The epidemiology of gall bladder disease: observations in the Framingham study. J Chron Dis 1966; 19: 273-92.

8 Williams CN, Johnston JL. Prevalence of gallstones and risk factors in Caucasian women in a rural Canadian community. Can Med Assoc J 1980; 120: 664-8.

9 Stolley PD, Tonascia JA, Tockman MS, Sartwell PE, Rutledge AH, Jacobs MP. Thrombosis with lowestrogen oral contraceptives. Am J Epidemiol 1975; 102: 197-208.

10 Boston collaborative drug surveillance programme. Oral contraceptives and venous thromboembolic disease, surgically confirmed gallbladder disease, and breast tumours. Lancet 1973; i: 1399-404.

11 Royal College of General Practitioners' oral contraception study. Oral contraceptives and gallbladder disease. Lancet 1982; ii: 957-9.

12 Diehl AK, Stern MP, Ostrower VS, Friedman PC: Prevalence of clinical gallbladder disease in MexicanAmerican, Anglo, and black women. South Med J 1980; 73: 438-43.

13 Layde PM, Vessey MP, Yeates D. Risk factors for gallbladder disease: a cohort study of young women at- 
tending family planning clinics. $J$ Epidemiol Com Health 1982; 36: 274-8.

14 Ramcharan S, Pellegrin FA, Ray R, Hsu J-P: The Walnut Creek contraceptive drug study. Bethesda, MD, NIH Publication, no. 81, 1981: 564.

15 Boston collaborative drug surveillance program. Surgically confirmed gallbladder disease, venous thromboembolism, and breast tumours in relation to postmenopausal estrogen therapy. $N$ Engl J Med 1974; 290: $15-9$.

16 Sampliner RE, Bennett PH, Comess LJ, Rose FA, Burch TA. Gallbladder disease in Pima indians. $N$ Engl J Med 1970; 283: 1358-64.

17 Williams CN, Johnston JL, Weldon KLM. Prevalence of gallstones and gallbladder disease in Canadian Micmac indian women. Can Med Assoc J 1977; 117: 758-60.

18 Bernstein RA, Werner LH, Rimm AA. Relationship of gallbladder disease to parity, obesity, and age. Hlth Serv Rep 1973; 88: 925-36.

19 Wheeler M, Hills LL, Laby B. Cholelithiasis: a clinical and dietary survey. Gut 1970; 11: 430-7.

20 van der Linden W. Some biological traits in female gallstone-disease patients. Acta Chir Scand 1961: suppl 269.

21 Sackett DL. Bias in analytic research. J Chron Dis 1979; 32: 51-63.

22 Mantel N, Haenszel W. Statistical aspects of the analysis of data from retrospective studies of disease. $J$ Natl Cancer Inst 1959; 22: 719-48.

23 Dales LG, Ury HK. An improper use of statistical significance testing in studying co-variables. Int $J$ Epidemiol 1978; 7: 373-5.

24 Breslow NE, Day NE. Statistical methods in cancer research. Vol 1. The analysis of case-control studies Lyon: IARC, 1980 .

25 Jørgensen T. Gallstones in a Danish population: Familial occurrence and social factors. J Biosoc Sci 1988 20: $111-20$.

26 vonBergmann $\mathrm{K}$, Becker M, Leiss $\mathrm{O}$. Biliary cholesterol saturation in non-obese women and non-obese men before and after puberty. Eur J Clin Invest 1986; 16: 531-5.

27 Bennion LJ. Changes in bile lipids accompanying oophorectomy in a premenopausal woman. $N$ Engl $J$ Med 1977; 297: 709-11.

28 Garn SM, LaVelle M, Rosenberg KR, Hawthorne VM. Maturational timing as a factor in female fatness and obesity. Am J Clin Nutr 1986; 43: 879-83.

29 Bennion LJ, Ginsberg RL, Garnick MB, Bennett PH. Effects of oral contraceptives on the gallbladder bile of normal women. N Engl J Med 1976; 294: 189-92.

30 Bennion LJ, Mott DM, Howard BV. Oral contraceptives raise the cholesterol saturation of bile by increasing biliary cholesterol secretion. Metabolism 1980; 29: $18-22$.
31 Kern F, Everson GT, De Mark B, et al. Biliary lipids, bile acids, and gallbladder function in the human female: Effect of contraceptive steroids. J Lab Clin Med 1982; 99: 798-805.

32 Pertsemlidis D, Panveliwalla D, Ahrens EH. Effects of clofibrate and of an estrogen-progestin combination on fasting biliary lipids and cholic acid kinetics in man. Gastroenterology 1974; 66: 565-73.

33 White CM, Howat JMT, Schofield PF. Lithogenic bile: a study in women taking oral contraceptives. Br J Surg 1976; 63: 664.

34 Everson GT, McKinley C, Lawson M, Johnson M, Kern $F$. Gallbladder function in the human female: Effect of the ovulatory cycle, pregnancy, and contraceptive steroids. Gastroentrology 1982; 82: 711-9.

35 Braverman DZ, Johnson ML, Kern F. Effects of pregnancy and contraceptive steroids on gallbladder function. $N$ Engl J Med 1980; 302: 362-4.

36 Frezza M, Chiesa L, Ricci C, et al: Gallbladder volume and contraction in non-pregnant women previously affected with intrahepatic cholestasis of pregnancy. Ital $J$ Gastroenterol 1985; 17: 311-3.

37 Anderson A, James OFW, MacDonald HS, Snowball S, Taylor W. The effect of ethynyl oestradiol on biliary lipid composition in young men. Eur J Clin Invest 1980; 10: $77-80$.

38 Down RHL, Whiting MJ, Watts JMcK, Jones W. Effect of synthetic oestrogens and progestagens in oral contraceptives on bile lipid composition. Gut 1983; 24: 253-9.

39 Tritapepe R, Padova CD, Zuin M, Bellomi M, Podda M. Lithogenic bile after conjugated estrogen. $N$ Engl J Med 1976; 295: 961-2.

40 Keane PF, Clanachan AS, Scott GW. Influence of age, gender, and progesterone on human gallbladder motility in vitro. Surg Forum 1984; 35: 467-8.

41 Coronary drug project: Gallbladder disease as a side effect of drugs influencing lipid metabolism: $N$ Engl J Med 1977; 296: 1185-90.

42 Everson RB, Byar DP, Bischoff AJ. Estrogen predisposes to cholecystectomy but not to stones. Gastroenterology 1982; 82: 4-8.

43 Kern F, Everson GT, DeMark B, et al. Biliary lipids, bile acids, and gallbladder function in the human female. Effects of pregnancy and the ovulatory cycle. $J$ Clin Invest 1981; 68: 1229-42.

44 Erfling W, McKinley C, Coan P, Showalter R, Kern F: Pregnancy in humans affect gallbladder function and the lithogenic index of bile. Gastroenterology 1978; 74: 1121.

45 Kirkinen P, Heikkinen J, Maentausta O. Gallbladder function and maternal bile acids in intrahepatic cholestasis of pregnancy. Eur J Obstet Gynecol Reprod Biol 1984; 18: 29-34.

46 Ylostalo P, Kirkinen P, Heikkinen J, Maentausta O. Gall bladder volume and serum bile acids in cholestasis of pregnancy. BrJ Obst Gynecol 1982; 89: 59-61. 